\title{
MEMÓRIAS DE UM JANTAR FRACASSADO: METONÍMIA DA RUÍNA FAMILIAR
}

\author{
Mariana Neto Silva Andrade \\ (Universidade Federal Fluminense)
}

\section{RESUMO}

O esplendor de Portugal (1997), obra do ficcionista português António Lobo Antunes, retrata, em planos separados, integrantes de uma mesma família. A mãe, Isilda, mora em Angola. Os três filhos, cuja infância foi vivida em África, residem agora em Portugal. O mais velho dos irmãos, Carlos, decide promover uma reunião entre irmãos no Natal de 1995. Toda a trama do romance, quando visto sob a perspectiva do trio, passa-se no dia 24 de dezembro, mostrando ora a expectativa de Carlos com a possível chegada dos irmãos, ora as considerações de Rui e Clarisse acerca do convite - o qual, por fim, ignoram. Neste trabalho, pretendemos, considerando em especial a personagem Carlos, observar como surpresa, expectativa e frustração se sucedem em torno da ideia de ceia natalina - e como a sua não realização sacramenta o definitivo esfacelamento do núcleo familiar.

PALAVRAS-CHAVE: O esplendor de Portugal, relações familiares, ceia.

\section{ABSTRACT}

O esplendor de Portugal (1997), work of the ficcionist António Lobo Antunes, portrays the members of the same family from different angles. The mother, Isilda, lives in Angola. The three children, whose childhood was lived in Africa, live in Portugal now. The oldest brother, Carlos, decides to promote a meeting among siblings during Christmas in 1995. When analyzed under the trio's perspective, the novel's plot happens on December 24, presenting sometimes Carlos' expectation of the possible arrival of his siblings, sometimes the considerations of Rui and Clarisse about the invitation - which, at the end, they ignored. Considering specially the character of Carlos, we intend in this present work, to observe how surprise, expectation and disappointment take place around the Christmas supper - and how its non-occurrence seals the definitive disintegration of the family unit.

KEYWORDS: O esplendor de Portugal, family relationship, Christmas supper. 
Ao discutirmos a ficção engendrada pelo autor contemporâneo português António Lobo Antunes, logo podemos nos remeter a determinados motes recorrentes, que nos auxiliam no traçado das características autorais mais marcantes. O romancista, que debutou com Memória de elefante, de 1979, costuma, efetivamente, ser identificado por particularidades formais e estilísticas. Quanto à forma, poder-se-ia mencionar a estrutura labiríntica das frases; a repetição incisiva de palavras/trechos, comumente associados a aspectos da vivência da personagem que se deseja destacar; a disposição das frases no papel, recordando, em variados momentos, a prática poética; a predileção pela polifonia, contrastando o discurso de diferentes personagens, a princípio díspares, mas que depois se revelam como membros de um mesmo núcleo social e/ou familiar; o jogo com os caracteres, eventualmente dispostos em itálico (prática desusada em suas obras mais recentes). Todos esses elementos concorrem para o poder de sedução que a escrita de Lobo Antunes exerce sobre seus leitores, além de ajudarem nas diferentes proposições e superposições de sentido encontradas ao longo de suas páginas, como bem atesta Dalva Calvão:

Escusado será dizer (sobretudo para os leitores habituais da obra de Lobo Antunes) que tal articulação ou desarticulação, entrevista em relação às ações, personagens, tempos e espaços do livro, será configurada e percebida, antes de tudo, na própria linguagem em que se tecem (e destecem) os fios da narrativa. Ou seja, a confusão temporal ou espacial, a relação tensa e contraditória entre as personagens, muito mais que referidas, muito mais que narradas, transparecem no próprio tecido narrativo, na radical corporificação de um verdadeiro amálgama entre conteúdo e expressão, ou entre fundo e forma, na exposição do que Barthes explicitará como a verdadeira transgressão levada a efeito pelo texto literário, aquilo que ele chamou "a responsabilidade da forma". Assim sendo, a possível desestabilização das certezas ou expectativas do leitor se inicia pelo contato com a frase fragmentada, com a palavra fragmentada, com os espaços em branco, com as repetições de palavras, de frases, de trechos inteiros, com as imagens obsediantes, com as onomatopeias, com a própria disposição gráfica não linear, com toda uma série de procedimentos, enfim, que, para além de determinarem um ritmo inesperado ao texto narrativo, desconcertam as chaves de leitura construídas a partir de outros moldes textuais. (CALVÃO, 2012, p. 331)

"A responsabilidade da forma", enunciada por Barthes em sua famosa Aula e recuperada acima por Calvão, envolveria um comprometimento primeiro com aquela que é a natureza básica do texto literário e ao mesmo tempo sua função primordial: desestabilizar expectativas previamente moldadas para permitir que se ouça "a língua fora do poder" (BARTHES, 2000, p. 8). António Lobo Antunes aplica a lição barthesiana ao fazer, por variados artifícios, com que as chaves de leitura em princípio criadas se rompam, em favor de uma leitura que, como bem disse o estu- 
dioso francês em outro texto famoso, promove a fruição. ${ }^{1}$ Podemos citar, a título de exemplo, o rompimento da linearidade cronológica, estratégia certamente já antiga em literatura, e que, revisitada pelo romancista português, ganha complexidade por intermédio do contínuo movimento entre passado e presente nos relatos de suas personagens. Ao pensarmos que as dicções múltiplas estabelecidas no romance seguem o ritmo veloz do pensamento - e que, por isso, não é raro que sinais de pontuação sejam ignorados, ou que uma frase ou ideia iniciada só venha a ser concluída muitas linhas depois -, podemos também depreender que Lobo Antunes exige de seus leitores um esforço redobrado, na tentativa de compor, caleidoscopicamente, o panorama da obra, e estabelecer quais são, afinal de contas, as relações paulatinamente desvendadas entre as personagens ali presentes.

A opção pela malha polifônica, característica da ficção autoral desde que transpôs a chamada "fase da aprendizagem", está presente em $O$ esplendor de Portugal, o qual é, certamente, um dos volumes mais famosos do autor. Nele vê-se uma narrativa centrada em um núcleo familiar formado pela mãe, Isilda, e seus três filhos, a saber: Carlos, Rui e Clarisse. Enquanto aquela vive em Angola, cuidando da propriedade da família, estes residem em Portugal. A trama se passa em espaços geográficos distintos, portanto, bem como engloba recortes temporais diferentes. A fala de Isilda espalha-se por entre os anos de 1978 (logo após a ida de seus rebentos para a metrópole) e 1995 (ano de sua morte). Já as falas de seus três filhos situam-se todas em uma mesma data: a véspera do Natal de 1995.

A irresistível ironia do título, a brincar com o verso do hino nacional português (que funciona como epígrafe para a obra), também desvenda outra das características antunianas: de um lado, o foco dirigido para a questão colonial, tema que interessa ao autor desde o princípio de sua jornada literária, e que se mescla com sua trajetória pessoal, tendo sido Lobo Antunes, como é amplamente conhecido, médico do exército português em Angola durante vinte e sete meses (experiência aventada, com ares de autobiografia, em Os cus de Judas); de outro, o retrato distópico da realidade portuguesa, propositalmente escancarando as ruínas de um povo outrora predestinado às grandes conquistas e que, ao ver romper-se seu domínio sobre Angola, também vê dissipar-se o último bastião de um sonhado - e rentável - império. Nesse sentido, a escolha d'A portuguesa escrito sob o espírito patriótico que dominou o país à época do Ultimato recebido da Inglaterra, em 1890 - para título e epígrafe configura, por si só, um gesto ousado de desconstrução.

O hino, que salienta a trajetória vitoriosa da pátria e destaca o caráter de predestinação do povo português - "nação valente e imortal" -, já foi redigido em um período histórico crepuscular e, em sua letra, insinua-se certa consciência do fato - pois é preciso levantar de novo o esplendor nacional. Aponta-se para o passado do país de forma laudatória, sendo o mesmo a fonte de inspiração para novas conquistas - "entre as brumas da memória / ó pátria sente-se a voz / de teus egrégios avós / que te há-de le- 
var à vitória”. Sintomática é também a menção às brumas, que envolveram D. Sebastião em seu desaparecimento e em meio às quais ele viria, um dia, ressurgido. António Lobo Antunes, por sua vez, mostra-nos a perda da última colônia ainda mantida, bem como a problemática questão dos retornados, portugueses que em África viveram e que, agora, deslocam-se de volta para seu país natal. $O$ autor português desvenda a complexa formação identitária da nação portuguesa, em processo que nos remete às palavras de Stuart Hall:

[...] as identidades nacionais não são coisas com as quais nós nascemos, mas são formadas e transformadas no interior da representação. Nós só sabemos o que significa ser inglês devido ao modo como a "inglesidade" (Englishness) veio a ser representada - como um conjunto de significados - pela cultura nacional inglesa. Segue-se que a nação não é apenas uma entidade política mas algo que produz sentidos - um sistema de representação cultural. As pessoas não são apenas cidadãos/ãs legais de uma nação; elas participam da ideia da nação tal como representada em sua cultura nacional. [...] O discurso da cultura nacional não é, assim, tão moderno como aparenta ser. Ele constrói identidades que são colocadas, de modo ambíguo, entre o passado e o futuro. Ele se equilibra entre a tentação por retornar a glórias passadas e o impulso por avançar ainda mais em direção à modernidade. As culturas nacionais são tentadas, algumas vezes, a se voltar para o passado, a recuar defensivamente para aquele "tempo perdido", quando a nação era "grande"; são tentadas a restaurar as identidades passadas. Este constitui o elemento regressivo, anacrônico, da história da cultura nacional. (HALL, 2011, p. 49 -57)

Nitidamente, vê-se na fala de Hall um panorama perfeitamente aplicável à realidade portuguesa, uma vez que, se sua história procura, por um lado, o ranço histórico ligado à predestinação, já desde as lendas que cercam a Batalha de Ourique, em 1139 - a qual foi supostamente precedida por uma visão advinda a D. Afonso Henriques, na qual Cristo lhe garantia a vitória sobre os mouros -, há, de outro, uma necessidade de reencontrar-se, sobretudo após os eventos históricos deste "breve século XX", como o denominou Hobsbawn. ${ }^{2} \mathrm{Na}$ história recente de Portugal vemos o longo período do Salazarismo, a perda das colônias africanas (em um intervalo de tempo que engloba treze anos, aproximadamente) e, por fim, os movimentos que culminaram no 25 de abril de 1974 - e o que dele adveio. Este último momento histórico, sobretudo, considerado por António Lobo Antunes não só em seu Esplendor como em algumas outras obras (tais como As naus, obra cáustica em seu parodismo), configura-se como talho profundo na constituição da identidade nacional, sendo ainda, uma não-inscrição histórica, tal como aponta o pensador contemporâneo José Gil: 
O 25 de abril recusou-se, de um modo completamente diferente, a inscrever no real os 48 anos de autoritarismo salazarista. Não houve julgamentos de Pides nem de responsáveis do antigo regime. Pelo contrário, um imenso perdão recobriu com um véu a realidade repressiva, castradora, humilhante de onde provínhamos. Como se a exaltação afirmativa da "Revolução" pudesse varrer, de uma penada, esse passado negro. Assim se obliterou das consciências e da vida a guerra colonial, as vexações, os crimes, a cultura do medo e da pequenez medíocre que o salazarismo engendrou. Mas não se constrói um "branco" (psíquico ou histórico), não se elimina o real e as forças que o produzem, sem que reapareçam aqui e ali, os mesmos ou outros estigmas que testemunham o que se quis apagar e que insiste em permanecer. (GIL, 2005, p. 16)

$\mathrm{O}$ fenômeno que Gil elucida não é exclusividade portuguesa. $\mathrm{O}$ próprio autor, no mesmo texto, alude à situação alemã pós Segunda Guerra Mundial, em sua ânsia de subscrever o III Reich e o nazismo; no Brasil, poderíamos pensar no movimento de Anistia, que, se permitiu o retorno dos exilados, também viabilizou o não-julgamento dos torturadores. Na nação peninsular, a negação de um fato histórico recente, atrelada a tantos outros ataques à identidade nacional, gerou uma crise identitária. O esplendor de Portugal, conforme muitos trabalhos já apontaram e outros ainda poderão melhor elucidar, muito se debruça sobre tal fato. Temos, a um só tempo, a personagem que fica em África, Isilda, a desvendar-nos o panorama que lá se encontra - "a tropa do Governo com um cabinda de alpercatas e óculos escuros intitulando-se alferes a subir as escadas da porta principal, a bater, a exigir a minha cama para si e o resto da casa para os soldados tontos de liamba que pegavam nas bazucas ao contrário" (ANTUNES, 1999, p. 75) e os personagens que para Portugal retornam, a reterem tanto a recordação dos dias em Angola quanto a consciência da nova realidade. O que a obra literária promove, em verdade, é o movimento de varredura daquilo que se esconde sob os tapetes, promovendo o reaparecimento dos estigmas e permitindo que se comece a "escovar a história a contrapelo", como sugere Walter Benjamin (1985, p. 232).

Entretanto, cremos que, para além do evidente retrato da contemporaneidade portuguesa, ressaltando as ruínas do império português, as páginas de $O$ esplendor de Portugal apresentam também, e de forma igualmente primorosa, a ruína de um núcleo familiar, enquadrando, aqui, não só a crise da cultura nacional, mas também a crise do sujeito pós-moderno, refém da fragilidade de suas relações afetivas. Ao pensarmos em como os laços afetivos são enquadrados no romance - as cartas que Isilda envia a seu filho Carlos são, por anos a fio, esquecidas, ainda lacradas, em uma gaveta; quando este tenta reunir os irmãos na época natalina, não obtém sucesso -, vemos que a sociabilidade, bem como a comunicação entre os pares, permanece danificada. Nesse ínterim, a tentativa frustrada de uma ceia (que ocorreria na casa de Carlos e de sua esposa, Lena) atua, no romance, como metonímia de uma relação familiar desgastada até o ponto da inviabilidade. 
Não nos esquecemos de que, aqui, ainda se flerta com a tradição, uma vez que "a alimentação é igualmente um domínio que ilustra com força a persistência das tradições nacionais e locais" (LIPOVETSKY; SERROY, 2011, p. 116). Sob a égide do (re)nascimento sugerida pela tradição cristã, a ideia de organizar uma reunião motivada pelos comes e bebes dezembrinos procura recuperar e reafirmar um hábito familiar em desuso naquele núcleo específico. A proposta de se promover uma ceia, no Natal de 1995, como oportunidade de celebração e, mais importante, de reencontro fraternal, já é indicada nas primeiras linhas do capítulo inicial da obra, narrado por Carlos, como que a indicar o simbolismo que a mesma tomará ao longo das páginas subsequentes. O leitor também já toma conhecimento, nesse momento, da distância existente entre mãe e filho e entre irmãos:

Quando disse que tinha convidado os meus irmãos para passarem a noite de Natal conosco

(estávamos a almoçar na cozinha e viam-se os guindastes e os barcos a seguir aos últimos telhados da Ajuda)

a Lena encheu-me o prato de fumaça, desapareceu na fumaça e enquanto desaparecia a voz embaciou os vidros antes de se sumir também

- Já não vês os teus irmãos há quinze anos

(a voz ao cobrir os caixilhos de vapor levou consigo os morros de Almada, a ponte, a estátua do Cristo a bater sozinha acima da bruma o desamparo das asas)

até que a fumaça se diluiu, a Lena regressou a pouco e pouco de dedos estendidos para o cesto do pão

- Já não vês os teus irmãos há quinze anos

de forma que de repente me dei conta do tempo que passara desde que chegamos da África, das cartas da minha mãe da fazenda primeiro e de Marimba depois, quatro cubatas numa encosta de mangueiras

(lembro-me da moradia do chefe do posto, da loja, de ruínas de quartel a naufragarem no capim)

os envelopes que guardava numa gaveta sem os mostrar a ninguém, os abrir, os ler, dúzias e dúzias de envelopes sujos, cobertos de carimbos e selos, falando-me do que não queria ouvir, a fazenda, Angola, a vida dela (ANTUNES, 1999, p. 9)

Lena, voz racional a se contrapor às esperanças vagas de Carlos, é aquela que, embora não fale por si própria (seu discurso é recuperado na dissensão narrativa do marido), mostra a nós, leitores, os evidentes fatores que competem para o insucesso da empreitada natalina, bem como, por meio de sua frase "Já não vês os teus irmãos há quinze anos", repetida incisivamente na trama - estratégia narrativa de evocação memorial bastante utilizada por António Lobo Antunes em suas obras -, é também a que primeiro nos traça um panorama de uma família marcada por rupturas, desvios e meias-verdades. Seu olhar externo, na condição de esposa de um dos irmãos, sugere que é o movimento de fora para dentro que nos fará 
notar as sutilezas dessa relação familiar deteriorada; parte-se do aspecto para enfim se alcançar, por via do discurso memorialístico, o foro íntimo dos acontecimentos.

É bastante característico da ficção antuniana a gradual revelação não só das relações existentes entre personagens que podem, a princípio, parecer díspares, mas também a leve e paulatina sugestão de complexas questões pessoais e interpessoais, fazendo com que o leitor desvende, por fim, um mistério antes apenas sugerido. Aqui, poderíamos recordar as palavras de Zygmund Bauman:

As identidades parecem fixas e sólidas apenas quando vistas de relance, de fora. A eventual solidez que podem ter quando contempladas de dentro da própria experiência biográfica parece frágil, vulnerável e constantemente dilacerada por forças que expõem sua fluidez e por contracorrentes que ameaçam fazê-la em pedaços e desmanchar qualquer forma que possa ter adquirido. (BAUMAN, 2001, p. 98)

Carlos é o centro de uma das mais importantes discussões a esse respeito. Sua figura constrói-se, ao longo do romance, por meio das reminiscências suas, de seus irmãos e de sua mãe; o lugar fixo cede espaço para a construção identitária partida, fragmentada. Ele é o menino a quem os empregados da fazenda encaravam por entre cochichos inexplicáveis; páginas depois, Isilda insinua a revelação por entre sua fala entrecortada - "o meu filho Carlos, o mais velho, o primeiro dos meus filhos e Deus sabe o que me custou aceitá-lo, aquele que toma conta dos irmãos em Lisboa e acha que eu não gosto dele por (...) eu não ser mãe dele”3 (ANTUNES, 1999, p. 80-81) -; por fim, o próprio Carlos a tomar consciência de sua origem mestiça, bastarda, constrangedora para ele, marcada pelos gritos de "Tu és preto" (ANTUNES, 1999, p. 99) que lhe lançavam.

É essa mesma personagem que, marcada pelo signo da diferenciação - e que, sendo mestiço e também retornado, duplamente encontra-se deslocado, sem pertencer nem a um, nem a outro lugar -, desejará romper a barreira de quinze anos que o separa do contato entre os irmãos mais novos. É certo que, a determinada altura do romance, Carlos já demonstra consciência de que viverá "meu Natal entre sobras de comida e garrafas vazias” (ANTUNES, 1999, p. 99); entretanto, ainda nas primeiras páginas, vemos que ele deposita, na imagem simbólica e familiar da ceia, o desejo de reatar os laços familiares já tão puídos. É o que nos mostra, por exemplo, o fragmento abaixo, em que se encontra seu extremo cuidado com a arrumação e o cardápio, assim como sua mal disfarçada ansiedade, a vigiar os ruídos da rua na expectativa de que fossem os irmãos finalmente chegando:

mandei um telegrama ao Estoril à Clarisse, falei ao telefone com o diretor do lar do Rui, avisei

- Às seis horas

avisei

- Estou à tua espera estou à espera dele às seis horas 
e portanto vão tocar a campainha de um momento para o outro, aposto que se começar a contar batem à porta antes de chegar aos cem, ouço um táxi a parar lá fora, o ônibus no apeadeiro da avenida, passos na escada e eu com a árvore de Natal por armar, falta meter o pinheiro no vaso e entornar cascalho para que fique direito, falta colocar a estrela de lantejoulas, $\mathrm{o}$ algodão da neve

algodão girassol arroz o gosto das papaias

as grinaldas, as bolas, embrulhar os bombons que comprei à Clarisse, a gravata que comprei ao Rui, o espumante no balde de gelo, os pratinhos de nozes e pinhões, a toalha de renda na mesa, o bolo-rei, o bacalhau, se contar de cem a zero, cem noventa e nove noventa e oito noventa e sete noventa e seis aposto que antes de chegar a dez entram ambos aí (ANTUNES, 1999, p. 18-19)

Interessante é constatar que, em eventuais passagens, a ceia é novamente invocada, e o leitor consegue perceber a sucessão dos acontecimentos: da mesa posta com os alimentos recém preparados à comida jogada na cesta de lixo; da esperança inicial de Carlos à sua fria constatação de que os irmãos não comparecerão. Torna-se, portanto, a ceia um símbolo da ruína familiar: tal como a celebração é malfadada, também se sacramenta, em definitivo, o malfadado relacionamento fraternal. Não é por acaso que a prerrogativa narrativa encontra-se "justamente nesse dia de Natal de que o romance parte" (SEIXO, 2002, p. 321): escolhe-se uma ocasião de tradicional reunião familiar como que a frisar, mais ainda, o não-acontecimento dessa mesma reunião.

Igualmente reveladora é a passagem que encontramos mais adiante, na qual Carlos admite considerar que o jantar entre irmãos poderia significar uma realidade familiar diferenciada. Nela, já enxergamos traços de uma leve frustração a infiltrar-se nessa personagem, sentimento replicado pela condição dos alimentos para a ceia - o espumante a perder a graça, os cubos de gelo a derreterem -, em representação metonímica da gradual consciência do desequilíbrio familiar. A seleção vocabular também indicia a mudança de perspectiva: a "árvore de Natal por armar" torna-se "pinheiro ridículo"; há laçarotes a disfarçarem o real valor dos presentes e sinos também "ridículos":

da mesma forma que estou sentado à mesa na Ajuda com a toalha de linho, o bolo-rei, as taças de amêndoas e broas e passas e pinhões, o espumante a perder a graça no balde de metal onde os cubos de gelo se dissolvem, a gravata e o frasquinho de perfume coroados de laçarotes que graças a Deus os fazem parecer mais caros, o pinheiro ridículo espetado no vaso com a estrela de lantejoulas no topo, enfeitado como uma cinquentona triste de grinaldas, pratas de bombons e sininhos patéticos, da mesma forma que estou aqui à espera, atento a cada táxi, cada camionete, cada automóvel na avenida na esperança de ouvir a campainha tocar e as vozes dos 
meus irmãos na rua, na esperança de que a Lena acabe depressa o filme da televisão, feche a revista, apague o cigarro (em tantos anos de casados nunca fui capaz de apagar decentemente um cigarro, sobra sempre uma linha de fumo que demora séculos a desaparecer)

e traga o caldo-verde e o bacalhau da cozinha, a Lena com a blusa e o colar de pérolas que eu gosto em lugar daqueles trapos cafuzos de mussequeira, a Lena, a Clarisse, o Rui e eu quinze anos depois como se estivéssemos em África, escutássemos o sopro do algodão no escuro, sentíssemos o cheiro da terra (ANTUNES, 1999, p. 46 -47)

A exposição que $O$ esplendor de Portugal faz, a nosso ver, não só acompanha o último ruir da grandeza nacional outrora proclamada, mas também expõe, na ausência dos irmãos à ceia programada, a falência de uma última tentativa de contato familiar, empreendimento falho e inviável após um passado coletivo conturbado e quinze anos de distância entre os irmãos, quando já vivendo em Portugal. Entretanto, como seria possível recuperar essa unidade familiar, após os acontecimentos que fizeram parte da história desse grupo e que aos poucos descobrimos? Aquilo que vemos, ao longo das páginas do volume, é o desenrolar de um denso e significativo drama familiar, marcado sobretudo pelo distanciamento e pela incomunicabilidade, esta, palavra-chave para compreendermos o sintagma das relações humanas na ficção de António Lobo Antunes. Se o distanciamento é, a princípio, geográfico - Isilda envia os três filhos para Portugal, permanecendo ela mesma junto às escassas posses da família em Angola -, as comunicações, propostas por carta, não se revelam eficazes; Carlos esconde - de si mesmo? - em uma gaveta as missivas maternas, sem lê-las, e, convocando os ausentes Rui e Clarisse para uma reunião no Natal, conta apenas com o silêncio de ambos diante da oferta. A omissão dos outros irmãos, no decorrer da leitura, é-nos revelada: Carlos expulsara a irmã de casa, alegando que a mesma era uma puta - para usar a terminologia do romance - e que não admitiria alojar uma pessoa com tal postura; quanto ao irmão, Carlos o internara em uma clínica e evitara-lhe o contato. Não é esse irmão mais velho, portanto, um inocente arauto da unidade familiar, como aos poucos descobrimos. E, se ele se cerca do bacalhau, das amêndoas, do bolo-rei e de outras opções culinárias características do período natalino para tentar recriar um ambiente caseiro e aconchegante, Clarisse se afastará de qualquer simbologia: "o Carlos e a Lena à minha espera no ninho de ratos da Ajuda e eu diante da televisão a comer pipocas, a beber Coca-cola e a mudar de canal" (ANTUNES, 1999, p. 311).

A essa altura da narrativa, o "Já não vês os teus irmãos há quinze anos" de Lena é substituído por "Ficamos à espera dos teus irmãos até de madrugada?” (p. 90). Por algum tempo, Carlos procura manter a ilusão da iminente chegada de Clarisse e Rui, ainda que a passagem das horas sem a presença destes seja demarcada pelos alimentos a esfriarem, sobre a mesa: 
os meus irmãos não chegaram ainda por causa do trânsito e das últimas compras, da chuva, dos arcos e lâmpadas e festões de Natal avenida fora, os grelos que esfriam, o bacalhau sem graça, o azeite coalhado, o bolo-rei cintilando as joias de pacotilha das cerejas cristalizadas e daqueles frutos que sabem a couve com açúcar (ANTUNES, 1999, p. 72)

dos jantares de cerimônia um acrezito de brotos entre leitões e cabras, melhor do que eu de terno novo na Ajuda, neste apartamento onde a árvore de Natal pisca lâmpadas de pacotilha e o bacalhau gela

e gela e gela e gela

no forno da cozinha (ANTUNES, 1999, p. 89)

Como enquadrar essa dissolução familiar em parâmetros? O indivíduo Carlos simboliza, também, o lugar do indivíduo na contemporaneidade: atravessado por informações variadas, deslocado em meio a relações sociais que urgem serem feitas, contando apenas com sua própria voz como meio de desbravamento da sua condição. Nesse sentido, a construção polifônica pretendida por António Lobo Antunes é oportuna, por permitir dar voz a seres atormentados e angustiados, a mônadas solitárias: ${ }^{4}$

Segue-se o que alguns analisam como a dissolução do vínculo social e a passagem das coletividades sociais ao estado de uma massa composta de átomos individuais lançados num absurdo movimento browniano. [...] Desde antes do seu nascimento, haja vista o nome que lhe é dado, a criança humana já é colocada como referente da história contada por aqueles que a cercam e em relação à qual ela terá mais tarde de se deslocar. Ou mais simplesmente ainda: a questão do vínculo social, enquanto questão, é um jogo de linguagem, o da interrogação, que posiciona imediatamente aquele que a apresenta, aquele a quem ela se dirige, e o referente que ela interroga: esta questão já é assim o vínculo social. (LYOTARD, 2008, p. 28-29)

Há, ainda, uma última observação que pode ser feita acerca da curiosa seleção da data presente no romance - 24 de dezembro de 1995 - para ser o marco referencial a partir do qual as reminiscências surgirão. Com efeito, se Carlos, Rui e Clarisse estão todos inseridos nesse recorte temporal, os capítulos destinados a Isilda espalham-se entre as datas de 24 de julho de 1978 e o mesmo Natal de 1995 do qual seus filhos falam, na construção da "diegese romanesca" de que nos fala Seixo (2002, p. 321). Em seu encerramento, o livro reafirmará o paradoxo simbólico que o marca: se, ao longo das páginas, vemos que um dia tradicional de reunião ajuda a enfatizar o retrato da família esfacelada, o encerramento da trama, com a morte de Isilda a ocorrer na mesma data em que ocorre a não-realização da ceia entre irmãos, sela o destino fragmentado familiar. Na data do nascimento de Cristo, Isilda morre, cordeiro expiado, justamente quando também sacramentara, em sintonia - ainda que não o soubesse - com seu filho Carlos: "E então decidi que este ano festejávamos o Natal em casa”, princi- 
pia o último capítulo da obra, por ela narrado (ANTUNES, 1999, p. 369). A matriarca, último elo possível entre os irmãos incomunicáveis, perece em Angola, último reduto do esplendor que Portugal costumava exibir.

A ceia, como forte símbolo natalino, permeia as páginas do romance, a traçar paralelos entre os alimentos que esfriam e o tempo que passa; o compasso de espera vivido por Carlos na noite de dezembro é sinalizado pela mesa posta, também - e constantemente - à espera. O fracasso familiar, portanto, é metonimicamente representado pelo insucesso da celebração. E a frase de Carlos, ao comentar que o prato de bacalhau "gela e gela e gela" parece promover, pelo eco, a perpetuação de um distanciamento que se descobre, para aquela família, irremediável.

\section{REFERÊNCIAS BIBLIOGRÁFICAS}

ANTUNES, António Lobo. O esplendor de Portugal. Rio de Janeiro: Rocco, 1999.

BARTHES, Roland. Aula. Trad. Leyla Perrone-Moisés. São Paulo: Cultrix, 2000.

BAUMAN, Zygmund. Amor líquido. Trad. Carlos Alberto Medeiros. Rio de Janeiro: Zahar, 2001.

BENJAMIN, Walter. Sobre o conceito de história. In: Magia e técnica, arte e política: ensaios sobre literatura e história da cultura. Trad. Sérgio Paulo Rouanet. São Paulo: Brasiliense, 1985, p. 222-232. (Obras escolhidas, v. I)

CALVÃO, Dalva. Na matéria e na alma: figurações barrocas na escrita de Lobo Antunes. In: Anais do XXII Congresso Internacional da Abraplip Memória, trânsitos, convergências. UFBA, 2012, p. 330-339.

GIL, José. O país da não-inscrição. In: Portugal, hoje: o medo de existir. Lisboa: Relógio d’Água, 2005, p. 15-23.

HALL, Stuart. A identidade cultural na pós-modernidade. Trad. Tomaz Tadeu da Silva e Guacira Lopes Louro. Rio de Janeiro: DP\&A, 2011.

LIPOVETSKY, Gilles; SERROY, Jean. A cultura-mundo: resposta a uma sociedade desorientada. Trad. Maria Lúcia Machado. São Paulo: Companhia das Letras, 2011.

LYOTARD, Jean-François. A condição pós-moderna. Trad. Ricardo Corrêa Barbosa. Rio de Janeiro: José Olympio, 2008.

SEIXO, Maria Alzira. Os romances de António Lobo Antunes. Lisboa: Dom Quixote, 2002. 


\section{NOTAS}

1 Referimo-nos, aqui, a O prazer do texto. Trad. J. Guinsburg. São Paulo, Perspectiva, 1987.

2 Fazemos referência à famosa obra de Eric Hobsbawn intitulada $A$ era dos extremos: $o$ breve século XX. Trad. Marcos Santarrita. São Paulo: Companhia das Letras, 2008.

$3 \mathrm{O}$ texto está em itálico no original, procedimento característico de alguns livros de António Lobo Antunes, conforme mencionamos no início do presente artigo.

4 Pensamos no conceito de mônada tal qual enunciado por Wilhelm Leibniz. Para este, o mundo é composto por uma imensidade de almas individuadas, cada qual vivendo de acordo com seus princípios internos e ansiando pelo contato com um outro possível. Vale a remissão à sua A monadologia e outros textos (Trad. Fernando Luiz Barreto Gallas e Souza. São Paulo: Hedra, 2009) 